Research article

\title{
Exotic species invasion threats to forests: A case study from the Betla national park, Palamu, Jharkhand, India
}

\author{
Preeti Kumari and A. K. Choudhary* \\ Department of Botany, Ranchi University, Ranchi-834002, Jharkhand, India \\ *Corresponding Author: ashokchoudhary.ru@gmail.com \\ [Accepted: 08 November 2016]
}

\begin{abstract}
Exotic Species Invasion (ESI) cause a little recognized, but very substantial impact to forest ecosystems worldwide. Climatic variability, physiographic range, increasing trade, travel and tourism have accelerated the spread of unwanted non-native species to conservation areas, making vulnerable to the establishment of ESI. Exotic Invasive Plants (EIPs) are known to displace native plants, alter ecosystems processes, hydrology, primary productivity, nutrient cycling and soil structure and most importantly reduce native biodiversity. There is evidence to suggest that the threats due to ESI may increase with climate change and associated changes in habitats. In this paper, we assess the threat of EIPs to natural forests in Betla National Park (BNP), Palamu in Jharkhand State, India. Based on intensive field surveys and using quadret method we identified 142 EIPs in the BNP forest. 21 plots of $20 \times 20 \mathrm{~m}$ for trees, $5 \times 5 \mathrm{~m}$ for shrubs and $1 \times 1$ $\mathrm{m}$ for herbs were laid randomly adjoining the forest at 10 to $100 \mathrm{~m}$ distance from the road and settlement area. Total 14 EIPs were recorded among which Lantana camara and Parthenium hysterophorus were found to be the most dominant species. . The survey revealed that apart from the ecological harm, invasive plants adversely affect the livelihood of all those who are dependent on forests. The paper identifies impact, early detection and rapid control, prevention of spread and habitat restoration as urgent measures for combating the threats.
\end{abstract}

Keywords: Exotic invasive plants - Risk assessment - BNP forest - Climatic change impact.

[Cite as: Kumari P \& Choudhary AK (2016) Exotic species invasion threats to forests: A case study from the Betla national park, Palamu, Jharkhand, India. Tropical Plant Research 3(3): 592-599]

\section{INTRODUCTION}

Exotic Species that become invasive are considered to be main direct drivers of biodiversity loss across the globe. Management of Exotic Species Invasion (ESI) is seen as major challenge in the field of biodiversity conservation. ESI, the non-native species threaten ecosystems, destroy habitats and create problems to other native species through invasion. It is considered as the second greatest agent of species endangerment and extinction. The ecological cost is often the irretrievable loss of native species and ecosystems. It also causes heavy economic loss, in terms of reduced crop and livestock production, reduced native biodiversity, increased production costs and so forth. Biodiversity has become one of the most popular topics for discussion at local, national and global level. Biodiversity entails all forms of biological entities inhabiting the earth including prokaryotes-wild plants and animals, microorganisms, domesticated animals and cultivated plants and even genetic material like seeds and germ-plasma (Kothari 1993). Exotic Invasive Species (EIS) are species, native to one area or region, that have been introduced into an area outside their normal distribution, either by accident or on purpose and which have colonized or invaded their new home, threatening biological diversity, ecosystems and habitats, and human wellbeing (CBD 2000). Biological invasion worldwide threatens biodiversity, ecosystem dynamics, resource availability, national economy and human health studied by (Ricciardi et al. 2000). The spread of EIS is now recognized as one of the greatest threat to the ecosystem. Exotic invasive species (animal pests, viruses, pathogens and plants) have become one of the most serious threats to the ecological and economic well-being of every habitat and region on the Earth (Boy et al. 2013). The introduction of alien species to a new location can either be accidental or intentional studied by (Enserink 1999). Accidental 
introductions are helped by travel across countries and continents and import of various items such as timber, food grains, fodder etc. (Shimono et al. 2008). Intentional introductions are for a variety of purposes such as agriculture, horticulture, forestry and ornamental (Cremer 2003). All invasive species possess certain biological attributes which contribute to their success as invaders in a new habitat. For invasive alien plants (IAPs), these attributes include production of a large number of easily dispersible, light weight seeds, fast growth rate and better competitive resource capture and utilization abilities compared to native plants (Burns 2006). The economic damage due to ESI is estimated to be to the tune of 1.4 trillion dollars globally. In many countries, the overall loss due to invasions is over $1 \%$ of the GDP. In the United States alone, for example, the annual costs of containing the spread of IAS are reported to be more than US\$ 135 billion (Boy et al. 2013). The impacts of IAPs include displacement of native plant species, change of soil chemical profile, rewarding pollinators better than the native species thereby reducing the reproductive success of local species, changing hydrological regimes, making the new habitat fire prone and limiting the photosynthetic efficiency of the local species by reducing light availability (Nilsson \& Grelsson1995). Subsequent impacts would happen by reduced availability of forest resources like medicinal plants from natural forests and timber from forest plantations. As in the classical case of Kaziranga National Park (Assam, India) where in the movement of the endangered one horned rhinoceros was limited by thickets of Mimosa diploticha var. diplotricha, the impact on fauna would also be critical studied by (Vattakkavan et al. 2002). Indirect impacts occur by way of complete elimination of food plants of the fauna and by making the habitat fire prone. It was believed that the threat of IES would be much low in natural habitats as compared to disturbed habitats. Forests were considered to be immune to large scale plant invasions. Climate change and the emergence of invasive alien plant species (IAPS), which are commonly referred as weeds, are two of the greatest threats to biodiversity and ecosystem services (Burgiel \& Muir 2010, IUCN 2000) defines IAPS as plants that have become established in natural or semi-natural ecosystems or habitats, an agent of change, and threatens native biological diversity. A study of (IPCC 2007) identified that climate change is one of the factors for emergence of invasive species. Increase in atmospheric temperatures and $\mathrm{CO}_{2}$ concentrations are likely to increase opportunities for the introduction of invasive species because of their adaptability and ability to disturb a broader range of bio geographic conditions and environments (Mooney 2000). A study by (Lodge et al. 2006) showed that IAPS endanger the environment, the economy and human welfare. It also reduces biodiversity, replaces important native species and increases investment in agriculture and silviculture operations (Ricciardi et al. 2000) and disrupts prevailing vegetation dynamics and nutrient cycling (Richardson \& Higgins 1998). The estimated damage from IAPS worldwide totals more than US \$1.4 trillionna year ( 5 percent of the global economy). Impacts affect a wide range of sectors including agriculture, forestry, aquaculture, transportation, trade, energy and recreation (Stern 2006).

The prime objective of the present paper is to report the Exotic Species Invasion (ESI) Threats to Forests in Betla National Park (BNP) Palamu, Jharkhand, India. We have also reported effect of ESI on different plant species, environment and different ecosystem etc. In addition to the above the preventive measures of ESI of National Park have been also studied.

\section{MATERIALS AND METHODOLOGY}

Study Area

Betla National Park (BNP) situated between latitude $23^{\circ} 25^{\prime} \mathrm{N}$ to $23^{\circ} 55^{\prime} \mathrm{N}$ and longitude $83^{\circ} 50^{\prime}$ to $84^{\circ} 36^{\prime} \mathrm{E}$, was notified in 1973 as one of India's first nine tiger reserves established under Project Tiger. It is located in the western part of the Chhotanagpur Plateau and spans an area of $1129.93 \mathrm{~km}^{2}$ comprising the Palamau Wildlife Sanctuary and Betla National Park is spread over Latehar, Palamau and Garhwa District in Jharkhand (Fig. 1). It is also part of the Central India Landscape and extends into the Sanjay-Dubri Tiger reserve and Achanakmar-Kanha tiger landscape through the Jashpur and Mahan forest of Chhattisgarh. The vegetation types mainly categorized as dry moist forest, dry Sal forest, moist Sal forest, high level plateau Sal forest and moist forest. BNP is also becoming home to many unwanted non-native plants. Very limited research has been carried out about ESI in BNP.

\section{Data collection}

Questionnaire survey was carried out from October 2015 to June 2016. Total 140 individuals who have long been inhabited in the study area and utilizing the local resources for their livelihood were interviewed to explore their perception regarding ESI. Total 21 sampling plots of various sized quadrates $20 \times 20 \mathrm{~m}$ for trees, $5 \times 5 \mathrm{~m}$ 
for shrubs and $1 \times 1 \mathrm{~m}$ for herbs were laid at 10 to $100 \mathrm{~m}$ distance in adjoining forest from road and human settlement area. Nested plots $5 \times 5 \mathrm{~m}$ and $1 \times 1 \mathrm{~m}$ quadrates were allocated randomly in two corners of $20 \times 20$ $\mathrm{m}$ plot (Tiwari et al. 2005, Bajpai et al. 2015). Community consultations, individual interviews, field observations, literature review, group discussions were conducted to collect data.

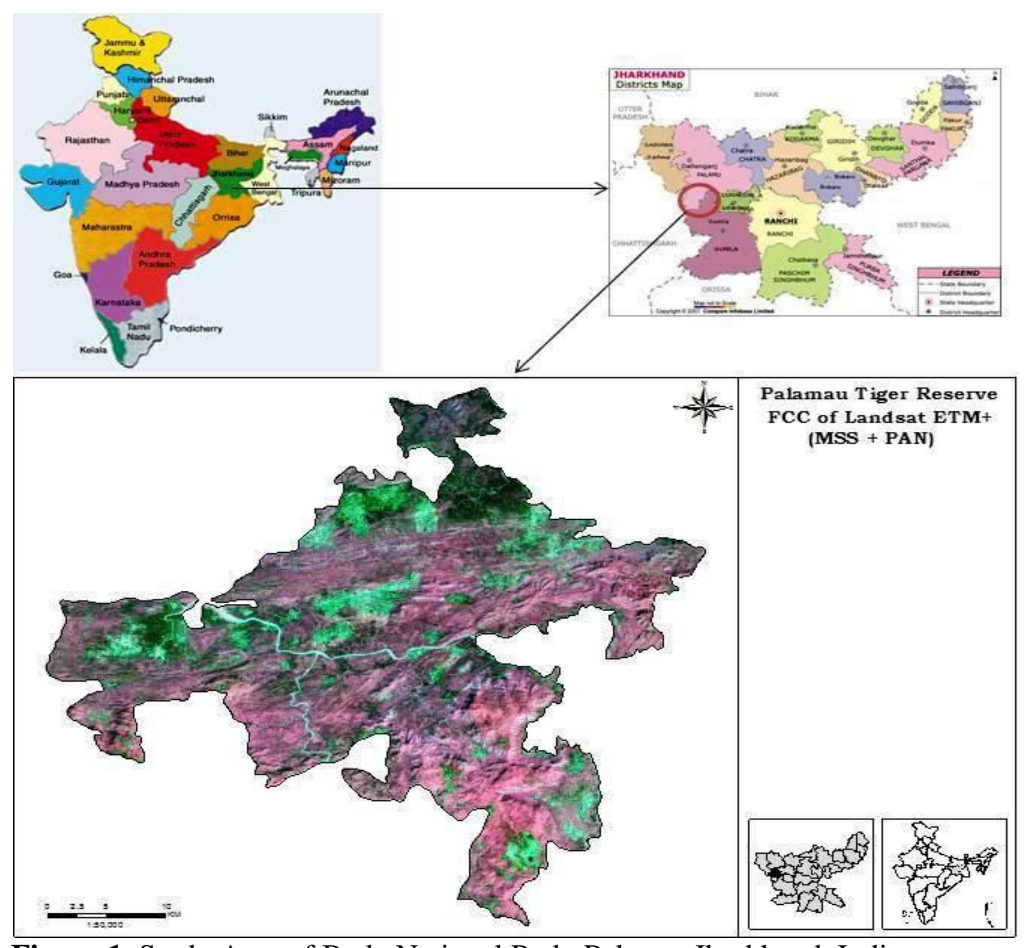

Figure 1. Study Area of Betla National Park, Palamu, Jharkhand, India.

Data analysis

Both quantitative and qualitative techniques were used for data analysis. By using following method density and frequency were calculated. The analysis was interpreted in a simple and understandable chart form. Density is an expression of numerical strength of a species in a community studied by using formula (Mishra 1968).

$$
\text { Density (D) }=\frac{\text { Total No. of individuals of a species in all the quadrates }}{\text { total number of quadrates studied }}
$$

Frequency denotes the number of sampling unite in which, a particular species occurs and so it expresses the distribution of dispersion of various species in community.

$$
\text { Frequency }(F)=\frac{\text { Total No. of quadrates in which the species occurred }}{\text { Total number of quadrates studied }} \times 100
$$

\section{RESULTS AND DISCUSSION}

\section{ESI in study area}

All together 14 EIPs were encountered in the sampled areas (Table 1). Among the ESI observed, Lantana camara \& Parthenium hysterophorus was most common in the study area. It has the highest cover in the adjoining forest, near settlement where human disturbances were high. Based on household survey Lantana camara \& Parthenium hysterophorus was found to be the most problematic ESI. An area where tree canopy is dense and the undergrowth do not find sufficient sunlight, invasion of species is low compared to open and degraded land. Therefore, with increasing tree canopy there is decreasing invasion of unwanted species. After Lantana camara \& Parthenium hysterophorus, Agertum houstonianum and Ipomoea purpurea, Ipomoea hederfolia were other to ESI found with high density in the study area. The spread of EIPs especially Perthanium hysterophorus complex and is threatening both the natural biological richness and livelihood of inhabitants. Many locals have stopped grazing their livestocks in forest as the palatable grasses in the forest like Imperata cylindrical, Cynodon dactylon are rapidly being replaced by the ESI especially by Perthanium hysterophorus. 
Table 1. Exotic Species Invasion (ESI) Observed in Betla National Park, Palamu, Jharkhand, India.

\begin{tabular}{llllll}
\hline S.N. & Specie & Introduction Purpose & Habitat & Origin \\
\hline 1 & Alternanthera brasiliana (L.) Kuntze & Intentional & Ornamental & Subshrub & Central \& South America \\
2 & Alternanthera philoxeroides (Mart.) Griseb. & Unknown & Unknown & Herb & South America \\
3 & Amaranthus spinosus L. & Accidental & NA & Herb & South \& Central America \\
4 & Ipomoea purpurea (L.) Roth & Intentiona & Ornamental & Climber & Central America \\
5 & Ipomoea hederifolia L. & International & Ornamental & Climber & Cenral America \\
6 & Jatropha gossypifolia L. & Intentional & Hedge plant & Shrub & Tropical America \\
7 & Lantana camara L. & Intentional & Ornamental & Shrub & Central \& South America \\
8 & Leucaena leucocephala (Lam.) de Wit & Intentional & Social forestry & Tree & Mexico \& Central America \\
9 & Merremia vitifolia (Burm.f.) Hallier f. & Accidental & NA & Climber & South Asia \\
10 & Mimosa pudica L. & Intentional & Ornamental & Herb & Tropical America \\
11 & Parthenium hysterophorus L. & Accidental & NA & Herb & North \& South America \\
12 & Prosopis juliflora (Sw.) DC. & Intentional & Fire wood & Tree & Central \& South America \\
13 & Sphagneticola trilobata (L.) Pruski & Intentional & Ornamental & Herb & South America \& West Indies \\
14 & Synedrella nodiflora (L.) Gaertn. & Accidental & NA & Herb & Tropical America \\
\hline
\end{tabular}

Effect of Exotic Species Invasion

Effects on ecosystem

After studies we found that invasive exotic plant species (IEPS) threaten the environment, reduce biodiversity, replace economically important plant species and increase the investment in agriculture and silviculture practices, prevail vegetation dynamics and alter nutrient cycling (Richardson \& Higgins 1998). They can promote hazards like forest fire. Plant invasions dramatically affect the distribution, abundance and reproduction of many native species (Sala et al. 1999). In the study area too, impacts of Invasive Exotic Plant species especially Parthenium hysterophorus was well observed and none of the ecosystems were free from their impact. Edges of forests, agricultural lands and wetlands have been severe IEPS intrusion. Although all ecosystems are susceptible to invasion, ecosystems entwined with higher level of human interventions (e.g. forestry, agriculture, wetland and rangelands) are likely to pose greater susceptibility (Yelenik et al. 2007). In the study site, rangeland, agriculture land as well as fallow lands and roadsides were highly susceptible to invasion of Ipomoea purpurea (L.) \& Ipomoea hederifolia L. IEPS (Fig. 2).

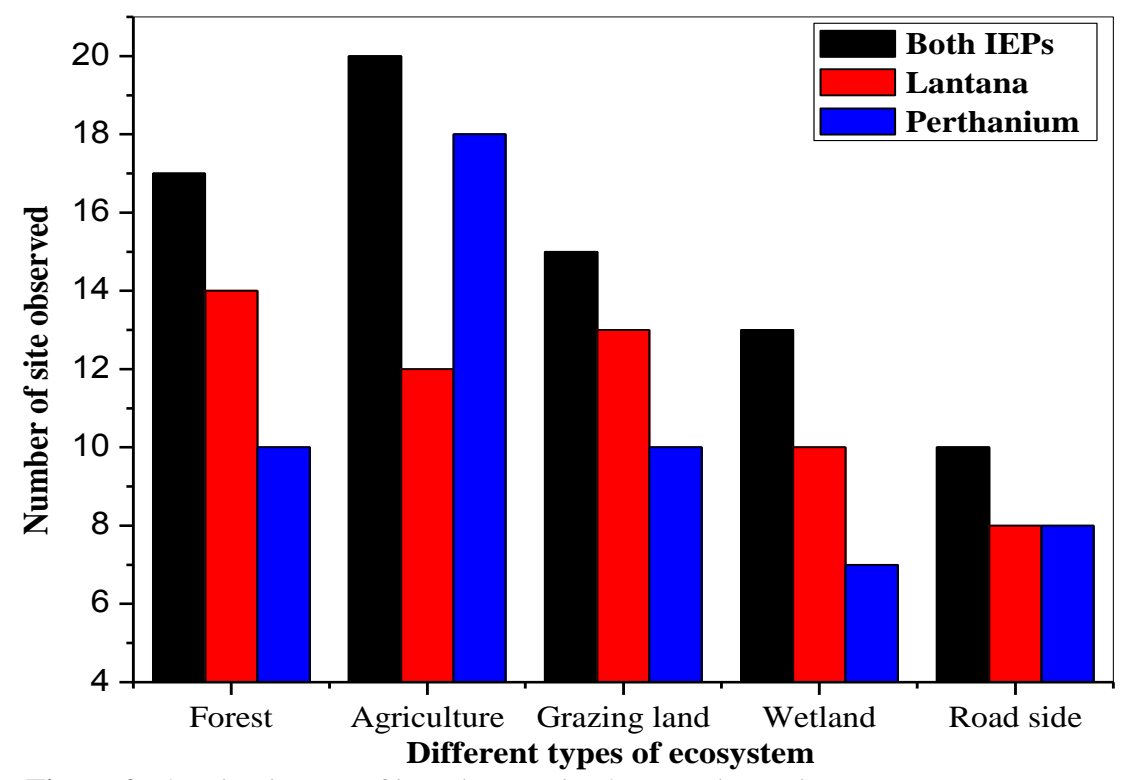

Figure 2. showing impact of invasive exotic plant species on important ecosystem.

\section{Effects on Forest}

As per surveys revealed that the forest, roadsides and fall low lands previously dominated by Alternanthera, Ipomoea, Jatropha, Lantana etc. were invaded by IEPS. Some plants failed to maintain their biomass in the changing climate and their dominance was fairly slacked off by IEPS. As a result, dense and diverse forests are 
more resistant to ecological invasion (Pimm 1984). However, forests in studied area has invaded about $20 \%$ area particularly forest edges and plantation forests of the studied ecosystem. These species suppress the growth of native trees, shrubs and grasses growing beneath or close to them. Subsequently foliage for wildlife animals is reduced leading to starvation and death of the animals.

\section{Effects on human ecosystem}

The full costs of invasions also include the social and health impacts of exotic invasive species on humans, in particular to the rural communities depending on forests. As a result of the impacts of exotic invasive species on native forest biodiversity, a loss of food sources and traditional medicines may be experienced thereby compromising not only the health of local people but also the livelihoods of those dependent on the collection and sale of such items for income. For small-scale landowners, exotic invasive species can also decrease the value of their land. Forest workers, as part of their jobs, and people living in and around forests are more exposed to exotic invasive species such as the reservoirs and hosts of many emerging infectious diseases. Examples of such diseases include Lyme disease, hay fever also known rhinitis, some immune disorders, eczema, Ebola and Marburg hemorrhagic fevers, malaria, yellow fever, leishmaniasis, trypanosomiasis and Kyasanur forest disease. People living in and around invaded forest areas may also suffer allergic or other negative reactions to the exotic invasive species themselves or to the measures used to control them such as chemical and biological pesticides. A commonly planted tree for land restoration and as a source of forest products, mesquite (Prosopis juliflora) is a major cause of allergies in India. Sensitivity to mesquite pollen has been shown to result in asthma, rhinitis and conjunctivitis. In some places, children living close to areas infested with Dendrolimus sibiricus have experienced significant allergic reactions to the hairy caterpillars that have entered their homes. The hairs on larvae and egg masses of gypsy moth (Lymantria dispar) also cause allergies in some people. All these invasive plants and trees have had serious socio-economic impacts and ultimately increased poverty in the local communities. Some area of the study site is densely populated by subsistence farmers and livestock rearing is an integral part of their livelihood.

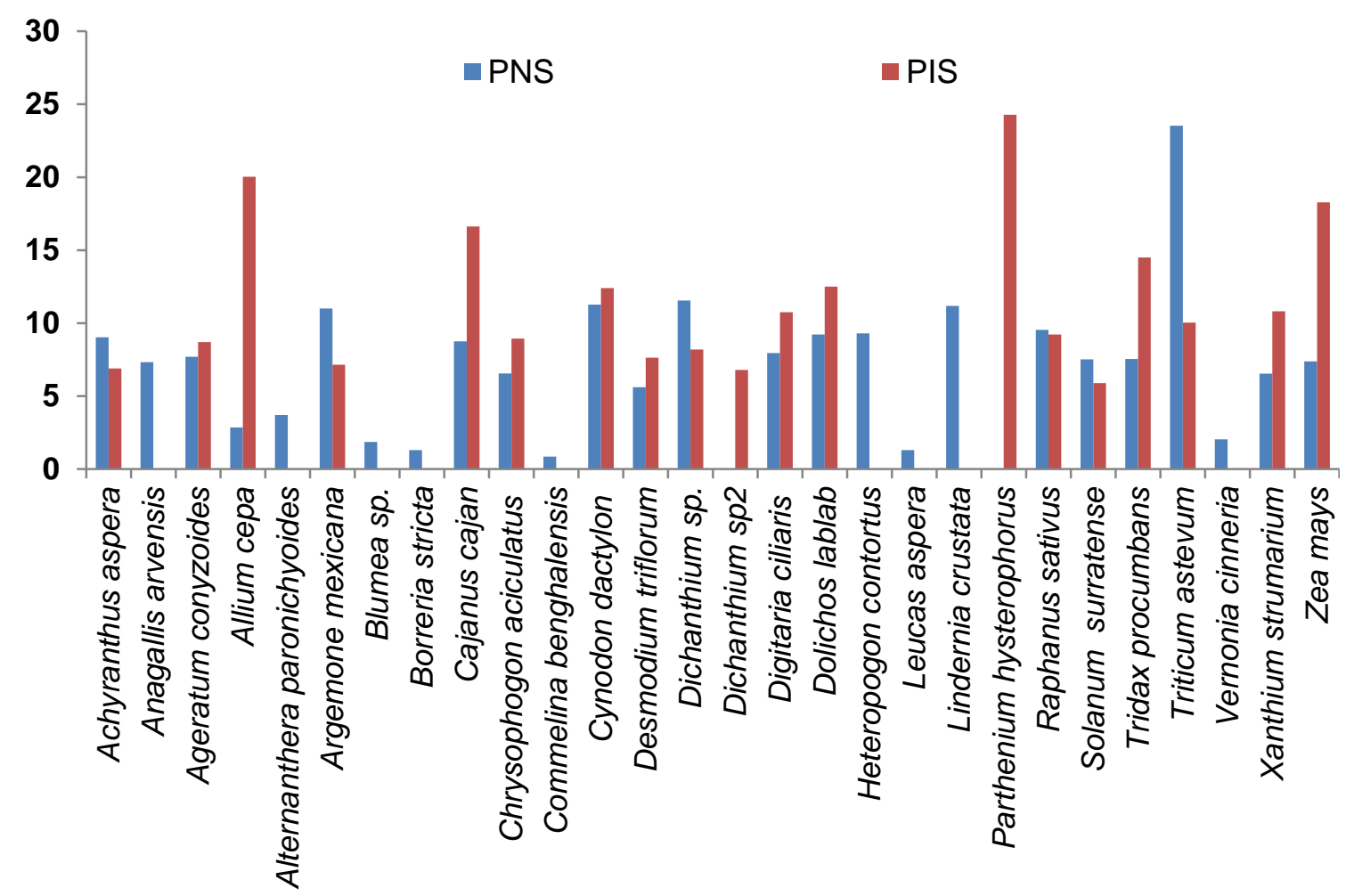

Figure 3. Reperesenting the comparative account of parthenium (exotic species invasion) non invaded and invaded study sites.

Impacts on Wetland and Rangeland Ecosystems

P. hysterophorus and I. purpurea is distributed throughout the study site; it can be just in any type of soil and environment. Nearby wetlands and throughout the rangeland is the most favourable environment for the 
invasion of invasive species. Apart from those species, water bodies of the study area were invaded by Jalkumbhi (Pistia stratiotes L.) and unwanted water favoring plants. I. purpurea mostly prefer damps areas such as wetland margins, drainage lines and gullies.

\section{Impact on Agricultural Ecosystem}

IEPS are also considered biological polluters and are capable of hybridizing with native plant relatives that result in genetically modified to a plant's genetic make-up results into great peril of biodiversity, which has also same impact in the study site. Parthenium hysterophorus has adverse impacts on most of the agricultural crops as nutrients and fertilizers supplied to the main crop are being exploited by this species (Fig. 3).

Agricultural crops, particularly ginger, millet, rice and grasses, were outcompeted by others and their productivity declined. Reduction in production of cereals and grasses in studied area as a result of invasion by Lantana, Perthanium. According to (Oerke et al. 1995) there was a loss of 13 percent of agricultural outputs due to weeds. Many grasses species, such as Artemisia spp, Solanum xanthocarpum and Urtica sp. of fallow lands and Scrophularia species, Hypoxis aurea etc. of agricultural lands were threatened by invasion of Perthaniums, Mimosa, and Sphagneticola invasive exotic plant species in the study site. Impact of P. hysterophorus on livestock is more severe in the study site. There are a number of livestock mortalities, particularly of buffaloes. The cases generally happened in the spring when the plant flowers are in full bloom. Similarly, IEPS affect the dynamics and composition of soil and have impacts on ecosystem functions, such as soil nutrient cycling and soil chemistry. In the study site, IEPS were growing in a wide range of soils but not flourishing in shade. Soil texture in agriculture land of the study area is silt clay.

\section{Methods to control of Exotic Species Invasion}

The following steps are proposed to manage existing EIPs and prevent any new incursions. Preventive measures

This study revealed the presence of invasion exotic plants in all the forest areas surveyed. It also showed direct and indirect impacts due to these invasions. It is recommended that a more comprehensive forest surveillance covering all the forest divisions in the State needs to be carried out before evolving proper control strategies. To prevent new incursions of ESI into forests, the following steps are to be adopted:

i. All plants, plant prop gules and soil intended for transportation into forest areas (soil for civil works, seedlings of forest tree species) should be thoroughly monitored for the presence of seeds and other prop gules of ESI.

ii. Import of seeds, seedlings and other prop gules of all plant species should be done only after risk assessment and observing proper quarantine procedures.

iii. Forest areas, especially those which are tourist destinations, need to have water filled dips at the entry point so as to wash agricultural implements and tires of vehicles free of ESI propagules before entering into forest areas.

\section{Early detection and rapid control}

The most economical way to contain ESI is to establish an efficient surveillance system so as to detect ESI soon after their arrival and eradicate them when their population is small and the spread is limited. To achieve this, sea ports, airports and tourist and pilgrimage routes into forest areas are to be monitored regularly for new invasive species using proper tools and methods. The staff of quarantine/customs and forest department need be trained to identify ESI which are potential threats so as to adopt measures to stop incursions and contain the population.

\section{Prevention of spread}

For ESI which have already established in some areas and immediate eradication is difficult, efforts should be focused on preventing their spread by:

1) Restricting the movement of soil and plant parts from infested areas to un-infested areas and

2) Removing the weeds manually or mechanically (cutting or pulling) before flowering and fruiting and burning them at the site.

\section{Habitat restoration}

Manual/mechanical control may be difficult, costly and unsustainable for exotic weeds which have established in large areas. In such cases, systematic restoration strategies should be taken up. To achieve this, 
remove the weeds manually or mechanically (pulling along with roots/tubers) in small areas at a time and subsequently plant the area with fast growing native species. Assisted regeneration may also be attempted in such areas.

\section{CONCLUSION}

Exotic Species Invasion (ESI) is a serious threat to forests of Jharkhand since they impact heavily on native biodiversity, productivity and result in landscape level changes. In this observation we have found that total 14 IEPs in covered area and some species like Lantana, Perthanium and Ipomoea purpurea are highly dominated over native resources. The invasion is more serious in agriculture land followed by disturbed sites, such as newly constructed earthen roads. The invasion is seriously affecting agriculture productivity. A few households are using these species for making compost manure and producing bio-briquettes for energy. Promoting biobriquette production and market linkage would help to improve the health condition of different ecosystems and provide additional income to local community. Furthermore, it supports controlling forest degradation and loss of biodiversity. The problem demands urgent attention. Prevention of new incursions can be achieved by adopting risk assessments before import of plants and planting material. Forest surveillance, early detection and rapid control, manual/mechanical removal of weeds followed by planting of native species and assisted regeneration are suggested as immediate steps to control invasion and reduce impacts. Herbicidal application in forest areas need to be avoided as far as possible.

\section{REFERENCES}

Bajpai O, Kushwaha AK, Srivastava AK, Pandey J \& Chaudhary LB (2015) Phytosociological status of a monotypic genus Indopiptadenia:A Near Threatened Tree from the Terai-Bhabar Region of Central Himalaya. Research Journal of Forestry 9(2): 35-47.

Boy G \& Witt A (2013) Invasive alien plants and their management in Africa. In: Synthesis Report of the UNEP/GEF Project 'Removing barriers to Invasive Plant Management in Africa (RBIPMA)', CABI, Africa.

Burgiel SW \& Muir A (2010) Invasive Species, Climate Change and Ecosystem-based Adaptation: Addressing Multiple Drivers of Global Change, GISP, Washington DC, USA and Nairobi, Kenya.

Burns JH (2006) Relatedness and environment affect traits associated with invasive and non-invasive introduced Commelinaceae. Ecological Applications 16: 1367-1376.

CBD (Convention on Biological Diversity) (2002) D ecision VI/23: Alien species that threaten ecosystems, habitats or species (Endnote I). Secretariat of the Convention on Biological Diversity, Montreal.

Cremer K (2003) Introduced willows can become invasive pests in Australia. Biodiversity 4: 17-24.

Enserink M (1999) Biological invaders sweep. Science 285(5435): 1834-1836.

IPCC (2007) Climate Change 2007: Impacts, Adaptation, and Vulnerability. Working Group II Contribution to the Intergovernmental Panel on Climate Change. Fourth Assessment Report. Summary for Policy Makers, IPCC, Geneva, Switzerland

IUCN (2000) IUCN Guidelines for the Prevention of Biodiversity Loss due to Biological Invasion. IUCN, Gland, Switzerland.

Kothari A (1993) Biodiversity conservation: for those vanishing species. Survey of environment, The Hindu, Madras.

Lodge DM, Williams S, MacIsaac HJ, Hayes KR, Leung B, Reichard S, Mack RN, Moyle PB, Smith M, Andow DA, Carlton JT \& McMichael A (2006) Biological invasions: recommendations for policy and management. Ecological Applications 16(6): 2034-2054.

Mishra R (1968) Ecology Work Book. Oxford and IBH Company, New Delhi, India pp. 244

Mooney HA (2000) Invasive Species in a Changing World. Island Press, Washington DC.

Nilsson C and Grelsson G (1995), The fragility of ecosystems: A review. Journal of Applied Ecology 32: pp. 677-692.

Oerke EC, Dehne H-W, Schönbeck F \& Weber A (1995) Crop Production and Crop Protection: Estimated Losses in major Food and Cash Crops. Elsevier, Amsterdam and New York.

Pimm SL (1984) the complexity and stability of ecosystems. Nature 307(5949): 321-326.

Ricciardi A, Steiner WWM, Mack RN \& Simerloff D (2000) Towards a global information system for invasive species. Bioscience 50(3): 239-244. 
Ricciardi A, Steiner WWM, Mack RN \& Simeroff D (2000) Towards a global information system for invasive species. Bioscience 50(3): 239-244.

Richardson DM \& Higgins SI (1998) Pines as invasion in the Southern hemisphere. In: Richardson DM (ed) Ecology and biogeography of Pinus. Cambridge: Cambridge University Press.

Sala OE et. al. (1999) Global change, biodiversity and ecological complexity. In: Walker B, Steffen WL, Canadell J \& Ingram JSI (eds) The Terrestrial Biosphere and Global Change: Implications for Natural and Managed Ecosystems. Cambridge University Press, Cambridge, UK.

Shimono Y \& Konuma A (2008) Effects of human-mediated processes on weed species composition in internationally traded grain commodities. Weed Research 48(1): 10-18

Stern N (2006) The Economics of Climate Change. HM Treasury, London, UK.

Tiwari S, Adhikari B, Siwakoti M \& Subedi K (2005) An inventory and assessment of invasive alien plant species of Nepal. IUCN, The World Conservation Union, Nepal.

Vattakkavan J, Vasu NK, Varma S, Gureja N \& Aiyadurai A (2002) Silent stranglers: Eradication of Mimosa in Kaziranga National Park, Assam. Wildlife Trust of India, New Delhi.

Yelenik SG, Stock WD \& Richardson DM (2007), Functional group identity does not predict invader impacts, Differential effects of nitrogen-fixing exotic plants on ecosystem function. Biological Invasions 9(2): 117125. 